\title{
New simple classification for operated bullous emphysema
}

\author{
Tommaso Claudio Mineo, MD, Vincenzo Ambrogi, MD, Eugenio Pompeo, MD, and Davide Mineo, MD
}

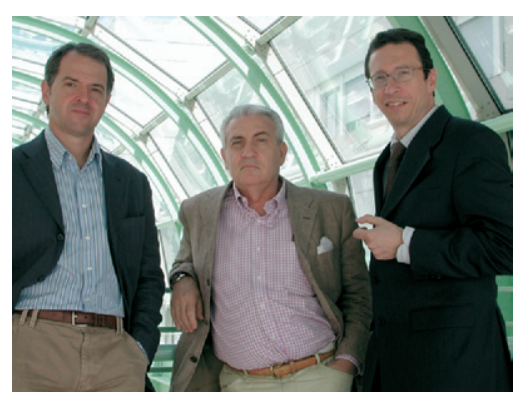

Drs Pompeo, Mineo, and Ambrogi
Objectives: Optimal results in bullectomy depend on both the size of the resected bulla volume and the reexpansion of the adjacent collapsed healthy pulmonary parenchyma. We hypothesized that the bigger the bulla is compared with residual volume, the greater are the possible benefits. We suggested a new prognostic classification according to bulla volume and its relationship with residual volume.

Methods: We retrospectively reviewed 121 patients with emphysematous bulla $(>200 \mathrm{~mL})$ who, from 1996 to 2006, underwent unilateral single $(\mathrm{n}=64)$, unilateral multiple $(\mathrm{n}=16)$, bilateral 1-stage $(\mathrm{n}=9)$, and bilateral 2-stage $(\mathrm{n}=32)$ bullectomies. Bulla volume and residual volume were measured by computed tomography and body plethysmography, respectively. Six-month postoperative decrement of residual volume values and their persistence below the baseline for 5 years were considered primary outcomes. Logistic regression was used to select significant variables. The receiver operating characteristic curve was used to identify the cutoff point for a possible classification system.

Results: There was no postoperative mortality. Significant postoperative improvements in respiratory function were found and correlated with bulla size. Residual volume improved in 75 patients $(62 \%)$ and persisted in 20 patients $(35 \%$ of the patients followed for $>5$ years). Logistic regression selected bulla/residual volume ratio as the most predictive variable for both outcomes $(P<.0001)$. The best cutoff individuated by the receiver operating characteristic curve analysis was $20 \%$ to achieve a high probability of residual volume improvement and $30 \%$ to minimize residual volume recurrence.

Conclusions: Bullectomy provides good results, but more significant and longlasting improvements are achievable with a greater ratio bulla/residual volume: scant for less than $20 \%$, good but temporaneous for $20 \%$ to $30 \%$, and good and long-lasting results for more than $30 \%$.

From the Thoracic Surgery Division and Emphysema Center, Policlinico Tor Vergata University, Rome, Italy.

This research was supported by grants from the CNR CU0100935CT26 2002 and Centro di Eccellenza 2001.

Received for publication Jan 21, 2007; revisions received April 3, 2007; accepted for publication April 11, 2007.

Address for reprints: Tommaso Claudio Mineo, MD, Cattedra di Chirurgia Toracica, Università degli Studi di Roma Tor Vergata, Policlinico Universitario Tor Vergata, Roma, Via Oxford, 8100133 Rome, Italy (E-mail: mineo@med.uniroma2.it).

J Thorac Cardiovasc Surg 2007;134:1491-7 $0022-5223 / \$ 32.00$

Copyright () 2007 by The American Association for Thoracic Surgery

doi:10.1016/j.jtcvs.2007.04.067
A bulla is defined as an air-filled space of $1 \mathrm{~cm}$ or more in diameter within the lung parenchyma as a result of progressive destruction of the alveoli. ${ }^{1,2}$ Bullectomy is generally considered the treatment of choice ${ }^{3-6}$ to avoid the potential risk of future pneumothorax, reexpand healthy areas of collapsed parenchyma, improve the respiratory dynamics, and, consequently, improve the quality of life in these patients. ${ }^{7-10}$ The introduction of video-assisted thoracic surgery with linear stapling sutures allows easier and safer resection. ${ }^{11}$ Short- and long-term results for this surgery have been reported, ${ }^{1,7,10,12,13}$ and better outcome is correlated with a greater volume of the resected bulla. ${ }^{14,15}$ We hypothesize that the bulla size may affect pulmonary hyperinflation, assuming it as a surgically modifiable component of the residual volume (RV). Thus, the bigger the bulla size is compared with the RV, the better and longer are the benefits achieved by bulla removal.

For many years, bulla volume has been accurately measured by computed tomography (CT), and RV has been precisely assessed by plethysmography. We reviewed our 10-year experience of surgery of bullous emphysema. Because of the relative low mortality and scant symptomatology of this condition, we selected the 


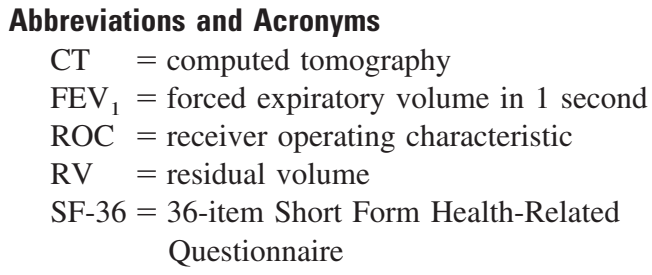

decrement of RV and persistence of RV below the preoperative values as primary outcomes. RV is a widely used marker of pulmonary hyperinflation; it is the most modifiable parameter by bulla removal and marginally influenceable by pharmacologic therapy. ${ }^{1,10,13}$ With the use of these two outcomes, we developed a new classification based on the parameter mostly modifiable by surgery: the ratio between the bulla and the RV.

\section{Materials and Methods}

\section{Patients}

From January 1996 to June 2006, 121 patients (108 male and 13 female; mean age $59.6 \pm 9.1$ years) with emphysematous bullae underwent bullectomies for unilateral single $(\mathrm{n}=64)$, unilateral multiple $(\mathrm{n}=29)$, and bilateral $(\mathrm{n}=32)$ disease. All patients but 9 declared to be smokers, 83 of whom were heavy smokers $(>30$ packs/year).

The radiologic evidence of emphysematous bullae greater than $200 \mathrm{~mL}$ in a parenchyma without evident signs of fibrosis was the main inclusion criteria. All patients were clinically stable and well nourished (body mass index $\geq 21 \mathrm{~kg} / \mathrm{m}^{2}$ ). The patients presented symptomatic difficulty in breathing, and 12 patients were oxygendependent. Twenty-two subjects also presented a significant sputum production. Concomitant pathologic conditions potentially affecting short-term survival were researched and excluded. An- other pivotal prerequisite was the absence or marginal presence of diffuse pulmonary emphysema requiring lung volume reduction surgery. One patient had alpha-1 antitrypsin deficiency.

\section{Pulmonary Assessment}

Preoperative evaluation always included pulmonary function and exercise testing. Forced expiratory volume in 1 second $\left(\mathrm{FEV}_{1}\right)$ was determined before and after bronchodilator inhalation to detect a spasm component, but only the best values after administration were chosen for data analysis. RV was determined by the plethysmographic technique (VMax Sensor Medics, Yorba Linda, Calif), and diffusion capacity for carbon monoxide was measured by the single-breath technique.

Enrollment criteria also required single-photon emission CT of the lung and cardiac echography with noninvasive estimation of the pulmonary artery pressure to be performed in all patients. Exercise tolerance was assessed by the standard 6-minute walk test. Dyspnea was evaluated according to the modified Medical Research Council Dyspnea Scale. ${ }^{16}$ Quality of life was assessed by means of the 36-item Short Form Health-Related Questionnaire (SF-36), whose score was expressed as a percentage from $0 \%$ (worst) to $100 \%$ (best). ${ }^{17}$ To simplify evaluation, the SF-36 general score was derived from the following formula: ([all answers score-lowest score possible/highest score possible] $\times 100)$.

\section{Pulmonary Imaging}

Imaging assessment started with digital inspiratory and expiratory posteroanterior and lateral chest radiography to evaluate the hyperinflation degree. Before 2001, the bulla volume was estimated by CT scan (Tomoscan SR 7000; Philips; Eindhoven, The Netherlands) according to the ellipsoid formula: ${ }^{18}$ volume $=1 / 4 \pi *$ transverse diameter $*$ sagittal diameter $*$ height.

Since June of 2001, the last 65 patients (Table 1) underwent both high-resolution and volume CT of the chest, acquired with the LightSpeed $^{16}$ scanner (General Electric Medical Systems, Milwaukee, Wis). The scans were appropriate for lung detail: thickness

TABLE 1. Study population who underwent operation for emphysematous bullae analyzed according to different periods

\begin{tabular}{|c|c|c|c|}
\hline Variables & 1996-2001 & 2001-2006 & $P$ value \\
\hline Patients (n) & 56 & 65 & NS \\
\hline Sex (M:F) & $50: 6$ & $58: 7$ & NS \\
\hline Age (mean \pm SD) & $58 \pm 9$ & $56 \pm 12$ & NS \\
\hline Bullae $(\mathrm{n})$ (mean $\pm \mathrm{SD} \mathrm{mL}$ ) & $83(743 \pm 501)$ & $98(737 \pm 392)$ & (NS) \\
\hline Giant bullae (>1000 mL) (No. of patients) & 18 & 22 & NS \\
\hline Pneumothorax (No. of patients) $(\%)$ & $11(19)$ & $13(20)$ & NS \\
\hline Bilateral disease (No. of patients) (\%) & $15(26)$ & $20(30)$ & NS \\
\hline Approach type (VATS: open thoracotomy) & $46: 26$ & $56: 28$ & NS \\
\hline Approach side (unilateral: bilateral) & $40: 32$ & $46: 38$ & NS \\
\hline 1-stage & 10 & 10 & \\
\hline 2-stage & 22 & 28 & \\
\hline Pain at $24 \mathrm{~h}$ (VAS 10-0) & $4.6 \pm 1.1$ & $3.7 \pm 1.3$ & .03 \\
\hline Air leakage ( $>7$ days) (No. of procedures) $(\%)$ & $16(22)$ & $18(21)$ & NS \\
\hline Drainage time (mean $\pm S D$ days) & $4.9 \pm 4.4$ & $3.4 \pm 2.1$ & .02 \\
\hline Hospital stay (mean \pm SD days) & $6.5 \pm 5.2$ & $5.3 \pm 2.2$ & .01 \\
\hline
\end{tabular}

NS, Not significant; $S D$, standard deviation; VATS, video-assisted thoracic surgery; VAS, Visual Analogue Scale. 
(1.25 mm), gap $(10 \mathrm{~mm})$, window width $(1500 \mathrm{HU})$, and level $(2600 \mathrm{H})$. The volumetric image acquisition was extended from the pulmonary apex through the diaphragm using these scan parameters: slice thickness of $3.75 \mathrm{~mm}$, reconstruction interval of 0.625 $\mathrm{mm}$, tube rotation of 0.8 seconds, $250 \mathrm{~mA}$, and $120 \mathrm{Kv}$. We used a 3-dimensional model to visualize the parenchyma, airways, and emphysema areas. By applying a minimum intensity projection reconstruction algorithm, we emphasized the emphysematous areas and used a manual tracing technique to segment bullae. The bulla volume was then automatically calculated. In the case of bilateral or multiple resected bullae, the volume was counted as unique.

\section{Surgical Technique}

The procedure was routinely performed through video-assisted thoracic surgery. We performed a total of 102 video-assisted thoracoscopies in 82 patients: 62 unilateral, 6 one-stage bilateral, and 14 two-stage bilateral procedures. Another 19 instances in 15 patients required conversion to an open procedure because of pleural adhesions, and these were included in the number of open thoracotomies. The remaining 35 procedures in 24 patients were approached through a lateral thoracotomy. From 2002, the procedure was carried out through sole epidural anesthesia in 23 patients.

A total of 181 bullae were resected (1.49 per patient and 1.16 per procedure). The mean volume of bulla per patient was $740 \pm$ $455 \mathrm{~mL}$ (range 201-2200 mL). No significant differences were detected between the 2 groups measured with different methods. The bulla was defined as giant whenever the volume was greater than $1000 \mathrm{~mL}$, and we reported this condition in 40 patients (33\%). Staged surgery was performed after a mean interval of $35 \pm 10$ days. The characteristics of the patients and procedures are summarized in Table 1. Bulla volume ranged between $4.7 \%$ and $53.1 \%$ of the RV (mean $22.5 \pm 13.0$ ), with 51 bullae smaller than $20 \%$ of the RV and 32 bullae more than $30 \%$.

Simultaneously to bulla resection, 5 patients underwent additional surgical procedures to resect incidental benign pulmonary nodules. Staple resection of great bullae and adjacent destroyed areas were routinely performed excising a single strip of lung tissue. Suture lines were buttressed with bovine pericardium in 22 cases. Bullae resection was performed by means of open or endoscopic linear stapling. A mean number of 6 stapling cartridges were used for each case.

Patients were always extubated in the operating room. Postoperative pain relief was achieved by a thoracic epidural catheter placed midline between the fourth and the fifth thoracic vertebral body. Postoperative care was provided in a thoracic step-down unit. Vigorous chest physiotherapy and ambulation were routinely carried out from 24 hours after surgery.

Postoperative evaluation included pulmonary function test, room air arterial blood gas analysis, 6-minute walk test, dyspnea, and quality of life questionnaires. Data were collected preoperatively and postoperatively at 6 month, 1 year, and yearly thereafter.

\section{Statistical Analysis}

Group descriptive statistics are presented as mean \pm standard deviation. Analysis of variance was conducted by 2 -tailed para- metric tests. A preliminary analysis of correlation between bulla volume and both respiratory and symptomatic variables was performed by the Pearson test using 12-month postoperative percentage changes.

Multivariate statistical analysis was performed by the stepwise logistic regression procedure with the Statistical Package for the Social Sciences software (version 10.00, SPSS Inc, Chicago, Ill) to identify the most predictive variables on outcome. Outcomes were considered the decrement of RV after 6 months from the procedure and the persistence of RV values below the preoperative values for a period of at least 5 years. In this case the evaluation was restricted to 56 patients with a follow-up of more than 5 years. Thereafter, among the significant variables, the receiver operating characteristic (ROC) curve was used to identify the cutoff point for a possible classification system. Kaplan-Meier estimate was used to draw the postoperative overall survival and survival free of recurrence of $\mathrm{RV}$. Whenever the value of postoperative $\mathrm{RV}$ was worse or unchanged compared with that of baseline, the event was considered failed.

\section{Results}

We had no postoperative deaths within 90 days from the operation. All patients were successfully extubated soon after the procedure. The mean chest drainage time was 4.2 days (range: 1-34 days). Prolonged air leaks for more than 7 days were described after 34 procedures $(22 \%)$, cardiac arrhythmia in $21(13 \%)$ and pneumonia in $6(4 \%)$. In-hospital stay ranged from 1 to 45 days (mean 5.7 days). Twenty-three patients were discharged with a chest tube and Heimlich valve.

\section{Early Functional Results}

The volume of residual bulla was recalculated 1 month after the operation by CT scan. Data were available in 106 patients. The volume of the residual bulla was considered as negligible in 88 patients $(83 \%)$, less than $10 \%$ of the preoperative value in 6 patients, and less than $20 \%$ of the preoperative value in 10 patients. In the remaining 2 patients with giant bullae, the size of the residual bulla was $35 \%$ and $45 \%$ of the preoperative value, respectively. Almost all functional measurements presented significant improvement after the procedure, and the changes lasted more than 5 years (Table 2). After 6 months, RV improved in 75 patients $(62 \%)$, decreasing from a mean baseline value of $3.7 \pm 1.9 \mathrm{~L}(167 \%)$ to $2.3 \pm 1.0 \mathrm{~L}$ (124\%). Before surgery the percentage of oxygen-dependent patients during exercise was $23 \%$. One year after surgery the percentage decreased to $17 \%$, eventually increasing to $21 \%$ after 5 years.

The Pearson correlation analysis showed that the volume of the resected bulla was positively correlated with the postoperative increment of $\mathrm{FEV}_{1}$ (Pearson coefficient $=.212, P=.04$ ) and the decrement of both RV $(-.218, P=.03)$ and dyspnea index $(-.203, P=.04)$. The bulla/RV ratio demonstrated a stronger positive correlation with $\mathrm{FEV}_{1}(.236, P=.02), \mathrm{RV}(-.262, P=$ $.01)$, dyspnea index $(-.214, P=.03)$, and quality of life improvement $(.199, P=.05)$. 
TABLE 2. Clinical results after bullectomy (all values expressed as mean \pm standard deviation)

\begin{tabular}{|c|c|c|c|c|c|}
\hline $\begin{array}{l}\text { Respiratory function } \\
\text { indexes }\end{array}$ & Baseline $(n=121)$ & $6 m(n=115)$ & 1 y $(n=102)$ & 3 y $(n=67)$ & 5 y $(n=46)$ \\
\hline Dyspnea index & $2.5 \pm 0.8$ & $1.5 \pm 0.9 \ddagger$ & $1.4 \pm 0.9 \ddagger$ & $2.0 \pm 0.8 \dagger$ & $2.0 \pm 1.0 \dagger$ \\
\hline $\mathrm{FEV}_{1}(\mathrm{~L})$ & $1.8 \pm 0.9$ & $2.2 \pm 1.2 \dagger$ & $2.3 \pm 1.0 \dagger$ & $2.0 \pm 1.2^{*}$ & $2.0 \pm 1.2^{*}$ \\
\hline $\mathrm{FEV}_{1}(\%$ of predicted) & $61 \pm 21$ & $69 \pm 16 \dagger$ & $69 \pm 17 \dagger$ & $66 \pm 24^{*}$ & $66 \pm 22^{*}$ \\
\hline $\mathrm{RV}_{\text {pleth }}(\mathrm{L})$ & $3.7 \pm 1.9$ & $2.3 \pm 1.0 \ddagger$ & $2.3 \pm 1.2 \ddagger$ & $2.6 \pm 0.8 \dagger$ & $2.9 \pm 0.5 \dagger$ \\
\hline $\mathrm{RV}_{\text {pleth }}(\%$ of predicted) & $167 \pm 80$ & $124 \pm 31 \ddagger$ & $124 \pm 37 \ddagger$ & $133 \pm 29 \dagger$ & $145 \pm 19 t$ \\
\hline $\mathrm{MIP}(\mathrm{mm} \mathrm{Hg})$ & $70.3 \pm 13.8$ & $85.2 \pm 16.4 \dagger$ & $82 \pm 11.5 \dagger$ & $80 \pm 14.4 \dagger$ & $79 \pm 13.8^{*}$ \\
\hline $\mathrm{MEP}(\mathrm{mm} \mathrm{Hg})$ & $82.2 \pm 12.6$ & $86 \pm 12.5^{*}$ & $89 \pm 13.4 \dagger$ & $86 \pm 11.5^{*}$ & $85 \pm 12.6$ \\
\hline DLCO ( $\%$ of predicted) & $58 \pm 18$ & $65 \pm 20 \ddagger$ & $65 \pm 20 \ddagger$ & $63 \pm 8 \dagger$ & $60 \pm 16 \dagger$ \\
\hline $\mathrm{PAO}_{2}(\mathrm{~mm} \mathrm{Hg})$ & $77 \pm 11$ & $81 \pm 11 \ddagger$ & $82 \pm 9.0 \dagger$ & $80 \pm 11 \dagger$ & $80 \pm 9^{*}$ \\
\hline $6 \mathrm{MW}(\mathrm{m})$ & $430 \pm 56$ & $495 \pm 40 \ddagger$ & $485 \pm 45 \ddagger$ & $475 \pm 108 \dagger$ & $471 \pm 23 \dagger$ \\
\hline $\begin{array}{l}\mathrm{O}_{2} \text { dependent } \\
\text { (No. of patients) }(\%)\end{array}$ & $9(23)$ & $5(13) \ddagger$ & $5(17) \ddagger$ & $4(17) \ddagger$ & $4(21) \ddagger$ \\
\hline SF-36 (\%) & $50.5 \pm 4$ & $79.2 \pm 3.9 \ddagger$ & $75.5 \pm 4.1 \ddagger$ & $70.5 \pm 5 \ddagger$ & $64.2 \pm 6.3 \dagger$ \\
\hline Physical function & $51.6 \pm 3.8$ & $70.5 \pm 4.9 \ddagger$ & $63.2 \pm 4.4 \ddagger$ & $61.3 \pm 2.4 \ddagger$ & $58.3 \pm 3.2 \dagger$ \\
\hline General health & $54.5 \pm 2.6$ & $72.5 \pm 2.5 \ddagger$ & $70.2 \pm 2.7 \ddagger$ & $68.2 \pm 3.6 \ddagger$ & $66.5 \pm 3.4 \dagger$ \\
\hline Social function & $62.5 \pm 3.0$ & $83.0 \pm 2.8 \ddagger$ & $78.8 \pm 2.9 \ddagger$ & $76.5 \pm 3.9 \dagger$ & $74.3 \pm 3.1 \dagger$ \\
\hline Mental health & $71.0 \pm 3.9$ & $81.2 \pm 3.5 \dagger$ & $80.1 \pm 3.7 \dagger$ & $80.0 \pm 3.6 \dagger$ & $77.3 \pm 3.3^{*}$ \\
\hline
\end{tabular}

$F E V_{1}$, Forced expiratory volume in 1 second; $R V$, residual volume; $M I P$, maximal inspiratory pressure; $M E P$, maximal expiratory pressure; $D L C O$, diffusion lung capacity carbon-monoxide; $P_{A_{2}}$, arterial blood oxygen partial pressure; 6MW, 6-minute walk test; SF-36, 36-item Short Form Health-Related Questionnaire. Baseline changes: ${ }^{*} P<.05 . \dagger P<.01 . \ddagger P<.001$.

\section{Long-term Survival Analysis}

The mean follow-up was $53 \pm 40$ months (range: $2-124$ months). We recorded a total of 13 deaths. The maximal mortality rate occurred during the first year. Six patients died as the result of acute exacerbation of the underlying chronic obstructive pulmonary disease. After 5 years, 1 patient died of pneumonia and 1 patient died of myocardial infarction. Kaplan-Meier survivals at 5 and 10 years were 93\% and $82 \%$, respectively (Figure 1).

As indicated in the "Materials and Methods" section, recurrence of disease was quantified using RV increment above the baseline values within 5 years from the procedure. At the end of our observation period, the values persisted below the baseline in 63 patients (52\%); 20 of 56 patients $(35 \%)$ had an observation period of more than 5 years. On Kaplan-Meier analysis, $40 \%$ and $8 \%$ of the population had no RV recurrence at 5 and 10 years, respectively (Figure 1).

None of the main mortality risk factors for obstructive pulmonary disease $\left(\mathrm{FEV}_{1}<50 \%\right.$, dyspnea index $>2$ or 6 -minute walk test $<350 \mathrm{~m})^{19}$ influenced the prognosis or $\mathrm{RV}$ recurrence probability (data not shown).

\section{Analysis of Prognostic Factors}

On multivariate logistic regression, the bulla/RV ratio was the only factor capable of directly influencing the decrement of $\mathrm{RV}(P<.0001$, odds ratio $1.18,95 \%$ confidence interval 1.11-1.26) and negatively influencing the recurrence of RV $(P<.0001$, odds ratio $0.88,95 \%$ confidence interval 0.83 0.92). The other variables considered (age, $\mathrm{FEV}_{1}, \mathrm{RV}$, dys- pnea index, 6-minute walk test, SF-36 score at the time of surgery) did not reach statistical significance.

Afterward, we applied the ROC curves for each outcome to find cutoff points within the continuous values of the bulla/RV ratio to dichotomize different categories of patients. ROC curve analysis individuated $20 \%$ as the best cutoff point to achieve a high probability of RV improvement (Figure 2). Below this value, only 14 of $51(27.4 \%)$ improved and none more than $-20 \%$ of the RV baseline value. Both sensitivity and specificity were satisfactorily high (Figure 2).

The other ROC curve evaluated RV recurrence as outcome and indicated $30 \%$ as the best cutoff to minimize RV recurrence. At a cutoff of more than 30\%, 29 of 32 patients (90.6\%) had no recurrence and 5-year recurrence-free survival was more than $50 \%$ with a high significance $(P<$ $.0001)$.

\section{Proposed Classification}

According to the results derived by the univariate and multivariate analyses, and ROC curve, we elaborated a new simple classification based on bulla/RV ratio (Table 3 ). When the ratio is greater than $30 \%$ and removal can be considered complete, the improvement of RV is frequent and usually significant, and RV recurrence probability is low. This delineates a class in which complete surgical removal may achieve a significant improvement in general health conditions (mean SF-36 change at 12 months, $47.6 \pm$ 32.3). 


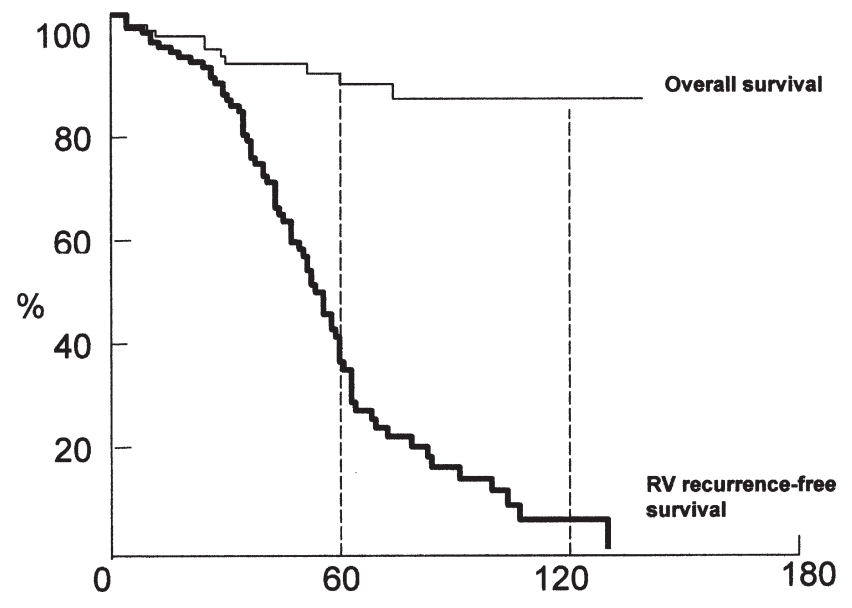

Figure 1. Survival curves for the entire study population. RV, Residual volume.

Ratios between $20 \%$ and $30 \%$ outlined an intermediate category with good immediate results but not as durable as the first class. In our study population, the SF-36 increment at 12 months was $21.1 \% \pm 19.9 \%$. On the other hand, when the ratio is less than $20 \%$, improvement is marginal and temporaneous with a high probability of RV recurrence and a scant improvement of quality of life at 12 months: $5.2 \% \pm$ $12.1 \%$ in our series.

\section{Discussion}

It is generally agreed that bullectomy improves lung function and, consequently, quality of life. ${ }^{1,10-13}$ However, the relative rarity of this condition hinders the completion of prospective randomized studies that match surgical results with those obtained by other therapies. Furthermore, the evaluation of the results is complicated by the scant symptomatology and difficulty of analyzing the values often obtained with subjective measurements.

The size of the bulla was always considered a fundamental discrimination factor in the choice of the treatment. ${ }^{14,15}$ When the bulla was too small, the surgery was considered unnecessary, and when the bulla was too big, the surgery was deemed technically impossible or even dangerous.

The development of lung volume reduction surgery for diffuse emphysema has allowed for a better understanding of the pathophysiology of the disease and disclosed new perspectives about the importance of the bulla size and the role of the RV. According to the National Emphysema Treatment Trial, ${ }^{20}$ bullectomy is the equivalent to lung volume reduction surgery in a diffuse emphysema with extreme heterogeneity. One may thus hypothesize that the bulla represents a significant part of RV and that bulla removal could imply an "ideal" lung volume reduction. ${ }^{21}$

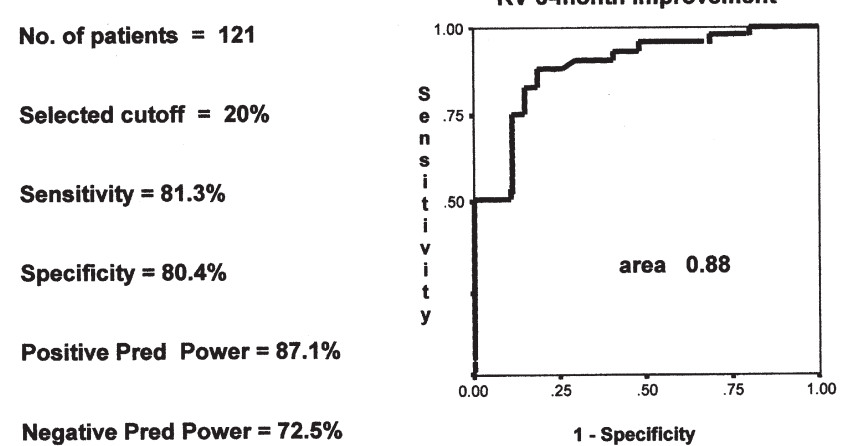

Negative Pred Power $=\mathbf{7 2 . 5 \%}$

RV 5-year recurrence

No. of patients $=\mathbf{5 6}$

Selected cutoff $=30 \%$

Sensitivity $=\mathbf{7 5} \%$

Specificity $=\mathbf{9 4 . 4} \%$

Positive Pred Power $=66.2 \%$

Negative Pred Power $=\mathbf{8 7 . 2} \%$

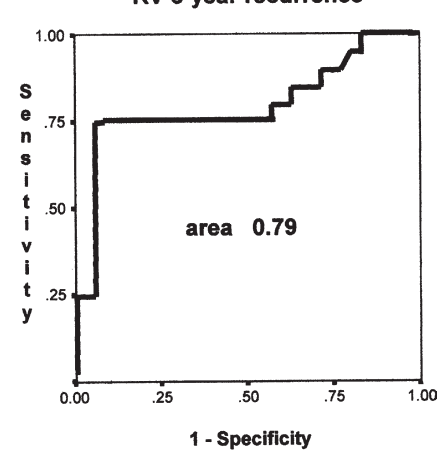

Figure 2. ROC curve for bullae/RV versus 2 different outcomes: RV improvement and $\mathrm{RV}$ recurrence. $R V$, Residual volume.

The higher the percentage represented by the bulla over the $\mathrm{RV}$, the more effective the operation.

This hypothesis could explain the direct relationship between the size of the bulla and the functional outcome described by some authors, ${ }^{14,15}$ and the excellent results reported for the surgery of giant bullae. ${ }^{1,10,13}$ Morgan and colleagues ${ }^{14}$ found a relationship between the improvement in functional parameters at 1 year and bulla size in 12 patients, hypothesizing an effect of reduction in lung volume. Baldi and colleagues ${ }^{15}$ demonstrated a strong relationship between the total lung capacity calculated by $\mathrm{CT}$ and the volumes determined by plethismography in 25 patients. Both of these studies somewhat anticipated the present study. The research of a precise instrumental measurement represented a limit in the development of this kind of surgery. Several previous studies have tried to correlate pulmonary function with imaging, ${ }^{10,11,14,15,18,22}$ and this is still a matter of investigation. However, in our study we demonstrated that CT technique may offer an effective and useful quantification of the bulla volume. At the same time, the differences in RV changes between estimation performed by body plethismography and by helium dilution may justify the scant functional results previously achieved by bulla resection ${ }^{10,23}$ and reinforce the concept of bulla as the "CT-evident" part of RV. Indeed, Becker and col- 
TABLE 3. Classification according to the volume of the resected bulla and residual volume ratio

\begin{tabular}{lcccc}
\hline Grade & Bulla/RV $\%$ & Improved RV at $\mathbf{6}$ mo & RV recurrence risk & $\begin{array}{c}\text { Quality of life expected } \\
\text { improvement at 12 mo }\end{array}$ \\
\hline I & $>30 \%$ & Frequent and significant $(>20 \%$ of baseline $)$ & Low $(<50 \%$ at 5 y) & High $(>25 \%)$ \\
II & $30 \%-20 \%$ & Frequent and significant $(>20 \%$ of baseline $)$ & High $(>50 \%$ at 5 y) & Medium $(10 \%-25 \%)$ \\
III & $<20 \%$ & Rare and marginal $(<20 \%$ of baseline $)$ & High $(>50 \%$ at 5 y) & Low $(<10 \%)$ \\
\hline
\end{tabular}

$R V$, Residual volume.

leagues $^{22}$ already showed that even total RV can be estimated with a good approximation by CT imaging according to specific algorithms.

Celli and colleagues ${ }^{19}$ recently proposed the multidimensional BODE index as an effective method for survival prediction in chronic obstructive pulmonary disease. Nevertheless, this instrument seems inadequate to define results in a disease with a low mortality rate, such as bullous emphysema.

In our study, we preferred to use RV as the most reliable index to indicate the immediate benefits of the procedure. This choice was made according to the following considerations. First, RV measured by plethismography is the physiologic parameter most severely impaired by the presence of a bulla. This justifies its decrement whenever the bulla is anatomically eliminated. Second, this parameter is not influenced by drug therapy and not subject to temporal variations. Third, it is easily, objectively, and periodically quantifiable by an instrumental test. For the evaluation of postoperative amelioration, we selected the timeframe of 6 months as the best compromise between the minimal traumatic effects caused by the operation and the maximal functional results caused by bulla removal.

We also deemed RV the most appropriate parameter to describe the temporal decay of the effects achieved by the procedure. Indeed, it is well known that the bulla rarely relapses $;{ }^{10}$ thus, the classic recurrence-free survival would not be applicable in this setting. In addition, the recurrence of dyspnea index was not appropriate either, given the subjective character of the test and the general poor symptomatology of these patients. According to the data from the follow-up of our population, we fixed the maximum timespan at 5 years to observe the recurrence of the preoperative RV.

In this study we found that the size of the bullae compared with RV represents an important positive predictive factor of postoperative improvement. More than two thirds of patients who underwent operation improved in dyspnea index within 3 months after the procedure. Many respiratory and functional parameters improved and remained stable for at least 2 to 3 years after surgery, declining without returning to the baseline values after 5 years and, in many instances, even after 10 years. These effects were correlated to the bulla/RV ratio. The rationale of this improvement is likely to be found in the reduction of pulmonary hyperin- flation and improvement in respiratory mechanics, as outlined by the correlation between the volume of the resected bulla and the clinical improvements. Many surgeons also consider the mechanical adverse effect, exerted by the bulla on the adjacent lung parenchyma, to have an influence on postoperative prognosis. ${ }^{24-26}$ Residual parenchyma reexpansion is unlikely in an otherwise totally altered lung. In the series presented by Witz and Roeslin, ${ }^{27}$ patients were divided into 2 groups: (1) those presenting localized bullous emphysema and (2) those showing bullae in the context of a destroyed emphysematous parenchyma. The former group had greater and long-lasting effects.

Our simple staging system aims at providing a guideline in predicting the amelioration and duration of the positive effects after bullectomy. The size of the bulla itself cannot predict the evolution of the disease because great bullae are often associated with adjacent altered parenchyma. This classification takes into account the RV value, which is a consistent part of the emphysematous disease and is also the quantifiable component of a collapsed adjacent parenchyma. All previous classifications ${ }^{27-29}$ tried with various expedients to conciliate these different aspects of the disease: the bulla and the emphysema. In our opinion, this method seems to be the easiest and the most reliable from the quantitative point of view.

The present classification does not pretend to be a rigid selection criteria for surgical treatment but only a method to predict patients'outcomes and consequently provide a stricter follow-up when necessary.

\section{Limitations}

We acknowledge some limitations in our study. First, the retrospective nature of the design, broad timeframe, and different measurement methods, because of the relative infrequency of the disease, are limitations. Second, the relatively small size and heterogeneity of our own study sample are limitations. Therefore, we intend to verify our results in a prospective multicenter study. Third, this classification is not applicable to patients with small bulla because a negligible size cannot significantly interfere with respiratory dynamics. In this case the main indication for surgery remains the prevention of pneumothorax. Fourth, the use of RV recurrence as outcome may encounter some difficulties in patients with excessive hyperinflation or nor- 
mal preoperative RV who had scant improvement from the procedure and were likely to demonstrate recurrence. Finally, the incomplete observation period for the last group of patients could explain the difference between the ROC curve area of RV recurrence and RV improvement.

\section{Conclusions}

We conclude that bullectomy is a safe and long-lasting procedure. Our simple classification based on bulla/RV ratio may provide a reliable method to predict the immediate functional and symptomatic effects and their duration. In patients with a ratio greater than $30 \%$, the decrement of RV is frequent and usually significant and RV recurrence probability is low. On the other hand, when the ratio is less than $20 \%$, improvement is marginal and transient with a high probability of RV recurrence and a scant improvement of quality of life.

\section{References}

1. Schipper PH, Meyers BF, Battafarano RJ, Guthrie TJ, Patterson GA, Cooper JD. Outcomes after resection of giant emphysematous bullae. Ann Thorac Surg. 2004;78:976-82.

2. Klingman R, Angelillo VA, DeMeester TR. Cystic and bullous lung disease. Ann Thorac Surg. 1991;52:576-80.

3. Benfield JR, Cree FM, Pellett JR, Barbee R, Mendenhall JT, Hickey RC. Current approach to the surgical management of emphysema. Arch Surg. 1966;93:59-70.

4. Potgieter PD, Benatar SR, Hewitson RP, Ferguson AD. Surgical treatment of bullous lung disease. Thorax. 1981;36:885-90.

5. Laros CD, Gelissen HJ, Bergstein PG, Van den Bosch JM, Vanderschueren RG, Westermann CJ, et al. Bullectomy for giant bullae in emphysema. J Thorac Cardiovasc Surg. 1986;91:63-70.

6. Wesley JR, Macleod WM, Mullard KS. Evaluation of surgery of bullous emphysema. J Thorac Cardiovasc Surg. 1972;63:945-55.

7. Fitzgerald MX, Keelan PJ, Cugell DW, Gaensler EA. Long-term results of surgery for bullous emphysema. J Thorac Cardiovasc Surg. 1974;68:566-87.

8. Pearson MG, Ogilvie C. Surgical treatment of emphysematous bullae-late outcome. Thorax. 1983;38:134-7.

9. Connolly JE, Wilson A. The current status of surgery for bullous emphysema. J Thorac Cardiovasc Surg. 1989;97:351-61.

10. Nikoladze GD. Functional results of surgery for bullous emphysema. Chest. 1992;101:119-22.

11. Deslauriers J, Leblanc P. Management of bullous disease. Chest Surg Clin North Am. 1994;3:539-59.
12. Greenberg JA, Singhal S, Kaiser LR. Giant bullous lung disease: evaluation, selection, techniques, and outcomes. Chest Surg Clin N Am. 2003;13:631-49.

13. Neviere R, Catto M, Bautin N, Robin S, Porte H, Desbordes J, et al. Longitudinal changes in hyperinflation parameters and exercise capacity after giant bullous emphysema surgery. J Thorac Cardiovasc Surg. 2006;132:1203-7.

14. Morgan MDL, Denison DM, Strickland B. Value of computed tomography for selecting patients with bullous lung disease for surgery. Thorax. 1986;41:855-62.

15. Baldi S, Palla A, Mussi A, Falaschi F, Carrozzi L, Giuntini C, et al. Influence of bulla volume on postbullectomy outcome. Can Respir J. 2001;8:233-8

16. Task Group on Screening for Respiratory Disease in Occupational Settings. Official Statement of the American Thoracic Society. Am Rev Respir Dis. 1982;126:952-6.

17. Ware JE Jr, Sherbourne C. The MOS 36-item short-form health survey (SF-36): I. Conceptual framework and item selection. Med Care. 1992;30:473-81.

18. Barnhard HJ, Pierce JA, Joyce JW, Bates JH. Roentgenographic determination of total lung capacity. A new method evaluated in health, emphysema and congestive heart failure. Am J Med. 1960; 28:51-60.

19. Celli BR, Cote CG, Marin JM, Casanova C, Montes de Oca M, Mendez RA, et al. The body-mass index, airflow obstruction, dyspnea and exercise capacity index in chronic obstructive pulmonary disease. $N$ Engl J Med. 2004;350:1005-12.

20. Rationale and design of the National Emphysema Treatment Trial (NETT): A prospective randomized trial of lung volume reduction surgery. J Thorac Cardiovasc Surg. 1999;118:518-28.

21. Snider GL. Reduction pneumoplasty for giant bullous emphysema. Chest. 1996;109:540-8.

22. Becker MD, Berkmen YM, Austin JHM, Mun IK, Romney BM, Rozenshtein A, et al. Lung volumes before and after lung volume reduction surgery. Am J Respir Crit Care Med. 1998;157:1593-9.

23. Gaensler EA, Cugell DW, Knudson RJ, FitzGerald MX. Surgical management of emphysema. Clin Chest Med. 1983;4:443-63.

24. Gunstensen J, McCormack RJM. The surgical management of bullous emphysema. J Thorac Cardiovasc Surg. 1973;65:920-9.

25. Foreman S, Weill H, Duke R, George R, Ziskind M. Bullous disease of the lung: physiologic improvement after surgery. Ann Intern Med. 1968;69:757-67.

26. Nakahara KM, Nakaoka K, Ohno K, Monden Y, Maeda M, Masaoka A, et al. Functional indications for bullectomy of giant bulla. Ann Thorac Surg. 1983;35:480-7.

27. Witz JP, Roeslin N. La chirurgie de l'emphysème bulleux chez l'adulte, ses résultats éloignés. Rev Fr Mal Respir. 1980;8:121-31.

28. Reid L. The Pathology of Emphysema. Chicago: Year Book Medical Publishers; 1967.

29. DeVries WC, Wolfe WG. The management of spontaneous pneumothorax and bullous emphysema. Surg Clin North Am. 1980;60: 851-66. 